\title{
The Effect of Endodontic Solutions on Resorcinol-Formalin Paste in Teeth
}

Madelyn Gay Gambrel

Virginia Commonwealth University

Follow this and additional works at: https://scholarscompass.vcu.edu/etd

Part of the Endodontics and Endodontology Commons

(C) The Author

\section{Downloaded from}

https://scholarscompass.vcu.edu/etd/797

This Thesis is brought to you for free and open access by the Graduate School at VCU Scholars Compass. It has been accepted for inclusion in Theses and Dissertations by an authorized administrator of VCU Scholars Compass.

For more information, please contact libcompass@vcu.edu. 


\section{School of Dentistry Virginia Commonwealth University}

This is to certify that the thesis prepared by Madelyn G. Gambrel entitled THE EFFECT OF ENDODONTIC SOLUTIONS ON RESORCINOL-FORMALIN PASTE IN TEETH

has been approved by his or her committee as satisfactory completion of the thesis or dissertation requirement for the degree of Master of Science.

Gary R. Hartwell, D.D.S., M.S., Thesis Director, School of Dentistry

Gary R. Hartwell, D.D.S., M.S., Committee Member, School of Dentistry

B. Ellen Byrne, Ph.D., D.D.S., Committee Member, School of Dentistry

Peter C. Moon, Ph.D., Committee Member, School of Dentistry

Gary R. Hartwell, D.D.S., M.S., Program Director, Chairman, Department of Endodontics

Dr. David Sarrett, Assistant Dean - Academic Affairs, School of Dentistry

Dr. F. Douglas Boudinot, Dean of the School of Graduate Studies

April 10, 2003 
(C) Madelyn G. Gambrel 2003

All Rights Reserved 
THE EFFECT OF ENDODONTIC SOLUTIONS ON RESORCINOL-FORMALIN

\section{PASTE IN TEETH}

A thesis submitted in partial fulfillment of the requirements for the degree of Master of Science at Virginia Commonwealth University.

by

MADELYN G. GAMBREL

B.A., Baylor University, 1993

D.D.S., University of Texas Health Science Center at San Antonio, 1997

Director: GARY R. HARTWELL, D.D.S., M.S.

CHAIRMAN AND PROFESSOR, DEPARTMENT OF ENDODONTICS

Virginia Commonwealth University

Richmond, Virginia

May 2003 


\section{$\underline{\text { Acknowledgement }}$}

This study was in part funded by a grant from the Alexander Fellowship Fund, Virginia Commonwealth University, Richmond, Virginia. The author wishes to thank several people. I would like to thank Drs. Ron Vranas and Peter C. Moon for all their

help and direction. Special thanks goes to Jared W. Cardon, who was an integral part of every phase of this project and who spent countless hours with me working on the project. The author would like to acknowledge Dr. Al Best for the statistical analysis. Most importantly, I would like to thank my program director and mentor, Dr. Gary R. Hartwell for his leadership, encouragement, wisdom, and support during the residency. 


\section{Table of Contents}

Page

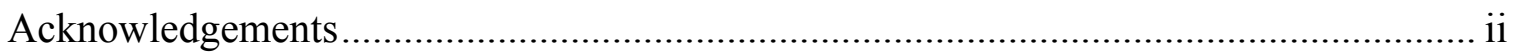

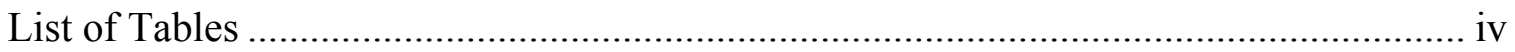

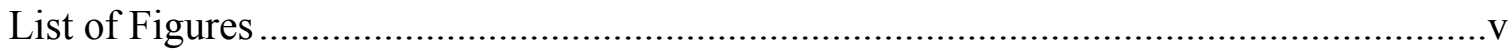

Abbreviations.............................................................vi

Abstract......................................................................

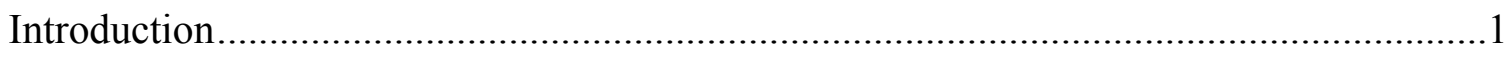

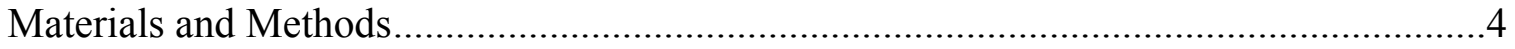

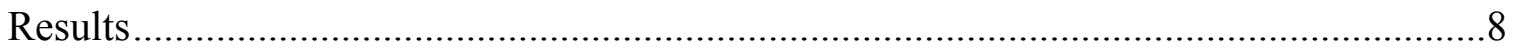

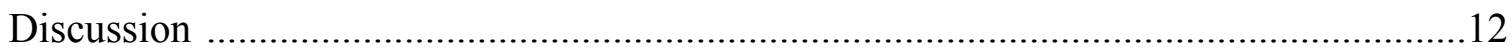

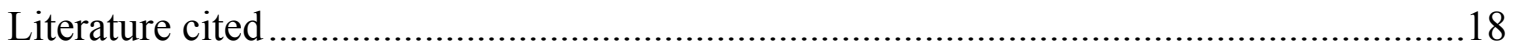

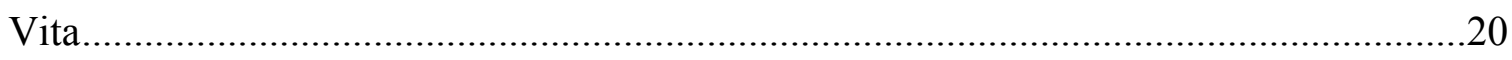




\section{$\underline{\text { List of Tables }}$}

Page

Table 1: Composition of resorcinol-formalin paste................................................

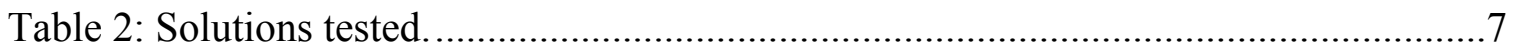

Table 3: Mean change in penetration across time.......................................................10 


\section{$\underline{\text { List of Figures }}$}

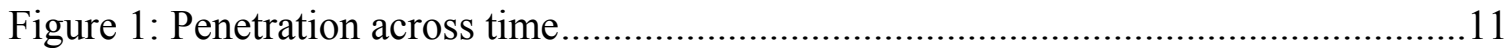




\section{$\underline{\text { Abbreviations }}$}

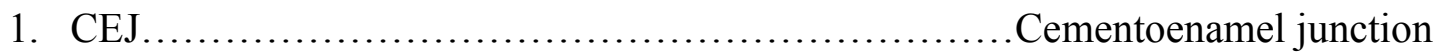

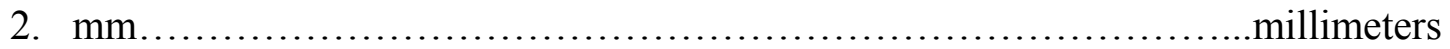

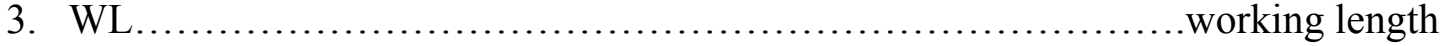

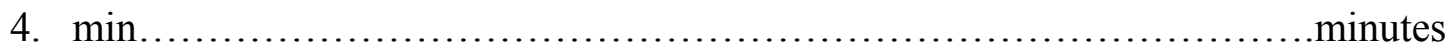

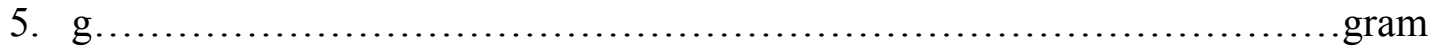

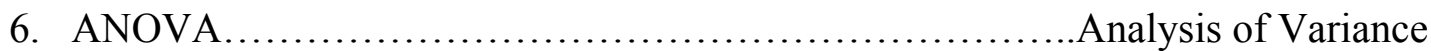

7. HSD ....................................... Honest Significant Difference

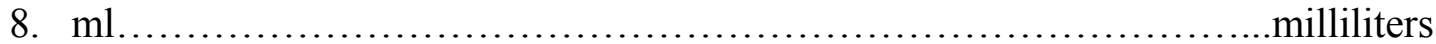




\begin{abstract}
$\underline{\text { Abstract }}$
THE EFFECT OF ENDODONTIC SOLUTIONS ON RESORCINOL-FORMALIN

PASTE IN TEETH

By Madelyn G. Gambrel, D.D.S.

A thesis submitted in partial fulfillment of the requirements for the degree of Master of Science at Virginia Commonwealth University.
\end{abstract}

Virginia Commonwealth University, 2003

Major Director: Gary R. Hartwell, D.D.S., M.S. Chairman and Professor, Department of Endodontics

This study determined if any of six endodontic solutions would have a softening effect on resorcinol-formalin paste in extracted teeth, and if there were any differences in the solvent action between these solutions. Forty-nine single-rooted extracted teeth were decoronated two mm coronal to the CEJ, and the roots sectioned apically to a standard length of $15 \mathrm{~mm}$. Canals were prepared to a $12 \mathrm{~mm}$ WL and a uniform size with a \#7 Parapost drill. Teeth were then mounted in a cylinder ring with acrylic. The resorcinolformalin mixture was placed into the canals and was allowed to set for 60 days in a humidor. The solutions tested were $0.9 \%$ sodium chloride, $5.25 \%$ sodium hypochlorite, chloroform, Endosolv $\mathrm{R}^{\circledR}, 3 \%$ hydrogen peroxide, and 70\% isopropyl alcohol. Seven 
samples per solution were tested and seven samples using water served as controls. One drop of the solution was placed over the set mixture in the canal, and the depth of penetration of a $1.5 \mathrm{~mm}$ probe was measured at $2,5,10$, and 20 min using a dial micrometer gauge. A repeated-measures ANOVA showed a difference in penetration between the solutions at $10 \mathrm{~min}(\mathrm{p}=0.04)$ and at $20 \mathrm{~min}(\mathrm{p}=0.0004)$. At $20 \mathrm{~min}$, Endosolv $\mathrm{R}^{\circledR}$, had significantly greater penetration than $5.25 \%$ sodium hypochlorite $(\mathrm{p}=0.0033)$ and chloroform ( $\mathrm{p}=0.0018)$; however, it was not significantly better than the control ( $\mathrm{p}=0.0812$ ). Although Endosolv $\mathrm{R}^{\circledR}$, had statistically superior probe penetration at $20 \mathrm{~min}$, the softening effect could not be detected clinically at this time. 


\section{Introduction}

The retreatment of endodontically failing teeth filled with hard pastes poses procedural problems to the clinician (1). There are no known solvents for certain types of hard pastes, and often the clinician is unable to determine what type of paste has been used in the canal (1). Friedman et al. (2) discuss mechanical means for removing hard-setting cements by either dispersion with ultrasonic vibration or drilling with rotary instruments. Clinical reports $(1,2)$ of ultrasonic dispersion indicate two disadvantages to this technique: 1) the technique is time consuming and files may be separated during the process and 2) alteration of canal shape in curved canals may occur with risk of perforation (2). Drilling with burs or rotary instruments is the fastest means for removing hard cements, but this technique also poses a high risk of perforating the root. The depth to which one is able to safely remove the hard paste is therefore limited.

Resorcinol-formalin resin is a paste filling material that is commonly used in Russia, China and India for the treatment of pulpitis (3). Although there are many variations of the resin pastes that are used, the main ingredients are resorcinol and formaldehyde. The principle behind "resinifying therapy" is that of a liquid phenolic resin being used which will solidify by polymerization after being placed into the root canal. The residual pulpal remnants are claimed to be "resinified" and to be "rendered harmless," and in this way to achieve a three-dimensional obturation of the root canal (4). However, 
when set, this material creates an almost impenetrable barrier and renders the tooth structure a deep brownish to red color. Due to remaining pulp tissue in the apical part of the canal, complete absence of cleaning and shaping procedures, and/or failure of the resinifying agent to reach the apical portions of the canal, this treatment may eventually fail, making retreatment of these teeth necessary.

As more patients migrate to the United States from countries where resorcinol paste filling materials are widely used, the question of how to remove this resin-based material becomes an important issue. Due to the lack of popularity of hard paste filling materials in the United States, there are few studies in the literature on the retreatment of canals obturated with pastes as the sole filling material (5). The studies that do exist on retreatment of hard pastes recommend a combination technique of commonly used endodontic solvents, rotary instruments and ultrasonics $(1,6)$. To date, two studies have examined the solubility of the different pastes. Cohen (5) studied the efficiency of different solvents and found formaldehyde resin pastes more difficult to dissolve than zincoxide pastes. These pastes lost less than $6 \%$ of their original weight after contact with a variety of solvents for one week. An introductory laboratory study on resorcinol-formalin paste by Vranas et al. (6) reported a significant softening of this type of paste when sodium hypochlorite and saline were tested on the set material in a dappen dish. A logical followup of Vranas'study would be to determine if similar results are obtained when the test solutions were placed into contact with the paste material after it had been placed and allowed to set in the root canals of extracted teeth. 
The purpose of this study was to determine if any of six common endodontic solutions have a significant softening effect on the set resorcinol-formalin paste in extracted teeth, and if there were any differences in the solvent action between these solutions. 
Materials and Methods

Forty-nine single-rooted extracted human teeth with fully formed apices were used for this study. After decontamination and removal of any periodontal soft tissue and bone, the teeth were stored in tap water for the duration of the experiment. The teeth were decoronated two $\mathrm{mm}$ coronal to the $\mathrm{CEJ}$, and the roots resected apically in order to obtain a standard length of $15 \mathrm{~mm}$. The access to the tooth root canal was enlarged with a \#557 carbide bur (SS White, Lakewood, NJ) in a high-speed handpiece to simulate a chamber which would serve as a reservoir for the test material. The root canals were prepared using Gates Glidden drills (Dentsply Maillefer, Tulsa, OK) sizes \#3-5 in a slowspeed handpiece to a working length of $13 \mathrm{~mm}$. They were then enlarged $1 \mathrm{~mm}$ short of the working length with Parapost drills \#6-7 (Coltene Whaledent, Mahwah, NJ) to obtain a root canal system of uniform size. After each instrument use the canals were irrigated with $2 \mathrm{ml}$ of $5.25 \% \mathrm{NaOCl}$, followed by a final flush with $5 \mathrm{ml}$ of saline at the completion of canal instrumentation.

Each specimen was then mounted in a phenolic ring form (Buehler, Lake Bluff, IL, USA) (internal diameter $21 \mathrm{~mm}$, height $19 \mathrm{~mm}$ ) with self-curing acrylic resin (Dentsply Trubyte Tray resin, Dentsply International Inc., York, PA, USA), leaving approximately 3 $\mathrm{mm}$ of the coronal portion of the tooth exposed. The teeth were mounted with their long axis perpendicular to the dial gauge stand (Mitutoyo, Japan). 
See Table 1 for the composition of the resorcinol-formaldehyde paste used. The resorcinol-formalin paste was mixed using the method described by Wu and Wang (7). The volume ratio of the three solutions is as follows: first solution $0.5 \mathrm{ml}$, second solution $0.5 \mathrm{ml}$, third solution $0.12 \mathrm{ml}$. The resultant mixture was placed into the canals. The canals were filled to a level just below the CEJ using a Monoject syringe (Sherwood Medical, St. Louis, MO, USA) with a 23 gauge needle. This created a $3 \mathrm{~mm}$ reservoir for the test solvent in the coronal portion of the prepared canal. The canals were sealed coronally with a thin layer of beading wax, and the specimens were stored in $100 \%$ humidity for 60 days to allow the paste to set completely.

The solutions tested were chloroform (Endoco, Memphis, TN, USA), Endosolv $\mathrm{R}^{\circledR}$ (Septodont, Saint-Maur, France), $5.25 \%$ sodium hypochlorite $(\mathrm{NaOCl})$ (Jones Austin Co., Mars, PA, USA), 0.9\% sodium chloride (Baxter, Deerfield, IL, USA), $3 \%$ hydrogen peroxide $\left(\mathrm{H}_{2} \mathrm{O}_{2}\right)$ (HUMCO, Texarkana, TX), and 70\% isopropyl alcohol (Henry Schein Inc., Melville, NY, USA) (Table 2). The forty-nine samples were divided into six test groups of seven samples per solution with an additional seven samples serving as controls with water as the control solution.

Each ring containing the specimen with the set resorcinol material was firmly secured to a dial gauge stand equipped with a flat-surfaced carbide needle $(1.5 \mathrm{~mm}$ diameter) used as a penetration probe loaded with a 115 -g weight. The carbide needle was pre-fitted in each tooth (prior to placement of the paste) to ensure that it would not bind on the walls of the root canal. The needle probe was lowered slowly onto the set resorcinol mixture in the canal and a baseline reading was taken from the dial gauge. This was 
repeated until two successive measurements yielded the same baseline reading. The needle was then raised and one drop of the test solution was placed in the chamber. The needle was again lowered onto the resorcinol and after $2 \mathrm{~min}$ the penetration of the needle was recorded. This process of raising the needle, placing a drop of the test solution, and lowering the needle was repeated at time intervals of 5, 10 and $20 \mathrm{~min}$ for each sample and test solution.

The total depth of penetration for each solution was determined by subtracting the 20-min depth measurement from the baseline measurement. The depth of softening of a sample at an individual time point was determined by subtracting each time period measurement from the previous time period measurement (i.e. the 2-min depth measurement was determined by subtracting the 2-min depth measurement from the baseline measurement; the 5-min depth measurement was determined by subtracting this measurement from the 2-min depth measurement, etc.). A repeated-measures ANOVA was used to test whether there was a non-zero penetration at each time interval and to test whether there was a significant difference between the six solutions. A comparison at each individual time point was assessed by Tukey's honest significant difference (HSD).

In a previous laboratory study by Vranas et al. (6), a power analysis based on comparable information in the Wennberg and Orstavik (8) report indicated that with a sample size of four, the study would have over $99 \%$ power to detect differences in penetrations of $0.075 \mathrm{~mm}$ or greater. This study was undertaken with a sample size of seven per solution. 
Table 1. Composition of resorcinol-formalin paste

Amount

Solution I:

Formaldehyde (Formalin)

(37\% USP, Polysciences, Inc., Warrington, PA)

$62.0 \mathrm{ml}$

Cresol

$12.0 \mathrm{ml}$

(Acros Organics, New Jersey, USA)

Ethyl Alcohol

$6.0 \mathrm{ml}$

(200 proof, 99.5\%, A.C.S. reagent, Aldrich, Milwaukee, WI)

Solution II:

Resorcin

(USP, Fisher Scientific, New Jersey, USA)

Distilled Water

$45.0 \mathrm{gm}$

$55.0 \mathrm{ml}$

Solution III:

Sodium hydroxide

(ACS reagent, Sigma Chemical Co., St. Louis, MO, USA)

Distilled water

$1.0 \mathrm{gm}$

Added to $2.0 \mathrm{ml}$

Table 2. Solutions tested

\begin{tabular}{ll}
\hline Solution & Manufacturer \\
\hline Chloroform & Endoco, Memphis, TN, USA \\
Endosolv $\mathrm{R}^{\circledR}$ & Septodont, Saint-Maur, France \\
$5.25 \%$ sodium hypochlorite $(\mathrm{NaOCl})$ & Jones Austin Co., Mars, PA, USA \\
$0.9 \%$ sodium chloride & Baxter, Deerfield, IL, USA \\
$3 \%$ hydrogen peroxide & HUMCO, Texarkana, TX \\
$70 \%$ isopropyl alcohol & Henry Schein Inc., Melville, NY, USA \\
\hline
\end{tabular}


Results

A repeated-measures ANOVA was used to assess the change in penetration across time, with the dependent variable being the change in penetration compared to the baseline. These averages are shown in Table 3. Figure 1 shows the different trends across time for each softening agent.

None of the groups differed from control at 2 or at 5 minutes. Endosolv $\mathrm{R}^{\circledR}, \mathrm{H}_{2} \mathrm{O}_{2}$, and saline demonstrated significant changes in mean penetration across time, while the other solvents did not exhibit any significant changes. At 10 and 20 minutes, the mean change in penetration with $\mathrm{H}_{2} \mathrm{O}_{2}$ was significantly less than the control. A repeatedmeasures ANOVA showed a difference in penetration between the solutions at 10 minutes $(\mathrm{p}=0.04)$ and at 20 minutes $(\mathrm{p}=0.0004)$. At 20 minutes, Endosolv $\mathrm{R}^{\circledR}$ had significantly greater penetration than $5.25 \%$ sodium hypochlorite $(\mathrm{p}=0.0033)$ and chloroform $(p=0.0018)$; however, it was not significantly better than the control $(p=0.0812)$.

Differences between the solutions at each time point were assessed using Tukey's honest significant difference. The $\mathrm{H}_{2} \mathrm{O}_{2}$ solution was excluded from this assessment because it was the only solution in which the change in penetration was negative. This result suggested an expansion of the paste material in $\mathrm{H}_{2} \mathrm{O}_{2}$ which makes the penetration measurement unreliable. At 2 and 5 minutes, the solutions were not significantly different $(\mathrm{p}=0.93$ and $\mathrm{p}=0.32$, respectively). At 10 minutes the solutions were significantly different 
$(p=0.0416)$. Although there was a significant difference between the solutions at 10 minutes, Tukey's HSD could not determine which solutions were different (at alpha $=0.05)$. At 20 minutes the solutions were significantly different $(p=0.0004)$. At 20 minutes, Tukey's HSD determined that chloroform and Endosolv $\mathrm{R}^{\circledR}$ had significantly different softening effects. None of the other solutions were different (at alpha $=0.05$ ) at 20 minutes. 
TABLE 3. Mean change in penetration across time

\begin{tabular}{|c|c|c|c|}
\hline Solution & Min & $\begin{array}{c}\text { Mean } \\
\text { Difference }\end{array}$ & $\begin{array}{c}\text { 95\% Confidence } \\
\text { Interval }\end{array}$ \\
\hline Chloroform & 2 & 0.0011 & $(-0.0094,0.0117)$ \\
\hline \multirow[t]{3}{*}{$(p=.9784)$} & 5 & 0.0019 & $(-0.0087,0.0124)$ \\
\hline & 10 & 0.0026 & $(-0.0080,0.0132)$ \\
\hline & 20 & 0.0031 & $(-0.0074,0.0137)$ \\
\hline Control $\left(\mathrm{H}_{2} \mathrm{O}\right)$ & 2 & 0.0021 & $(-0.0084,0.0127)$ \\
\hline \multirow[t]{3}{*}{$(p=.0601)$} & 5 & 0.0056 & $(-0.0050,0.0162)$ \\
\hline & 10 & $0.0113 *$ & $(0.0007,0.0219)$ \\
\hline & 20 & $0.0141 *$ & $(0.0036,0.0247)$ \\
\hline ЕTOH & 2 & 0.0063 & $(-0.0043,0.0169)$ \\
\hline \multirow[t]{3}{*}{$(p=.0772)$} & 5 & 0.0099 & $(-0.0007,0.0204)$ \\
\hline & 10 & $0.0137 *$ & $(0.0031,0.0243)$ \\
\hline & 20 & $0.0184 *$ & $(0.0078,0.0290)$ \\
\hline Endosolv R & 2 & 0.0033 & $(-0.0073,0.0139)$ \\
\hline \multirow[t]{3}{*}{$(\mathrm{p}<.0001)$} & 5 & 0.0064 & $(-0.0042,0.0170)$ \\
\hline & 10 & $0.0196 *$ & $(0.0090,0.0302)$ \\
\hline & 20 & $0.0276 *$ & $(0.0170,0.0382)$ \\
\hline $\mathrm{H}_{2} \mathrm{O}_{2}$ & 2 & -0.0030 & $(-0.0136,0.0076)$ \\
\hline \multirow[t]{3}{*}{$(\mathrm{p}<.0001)$} & 5 & -0.0117 & $(-0.0223,-0.0011)$ \\
\hline & 10 & -0.0189 & $(-0.0294,-0.0083)$ \\
\hline & 20 & -0.0370 & $(-0.0476,-0.0264)$ \\
\hline $\mathrm{NaOCl}$ & 2 & 0.0001 & $(-0.0104,0.0107)$ \\
\hline \multirow[t]{3}{*}{$(p=.6633)$} & 5 & 0.0006 & $(-0.0100,0.0112)$ \\
\hline & 10 & 0.0046 & $(-0.0060,0.0152)$ \\
\hline & 20 & 0.0047 & $(-0.0059,0.0153)$ \\
\hline Saline & 2 & 0.0031 & $(-0.0074,0.0137)$ \\
\hline \multirow[t]{3}{*}{$(p=.0096)$} & 5 & $0.0124 *$ & $(0.0018,0.0230)$ \\
\hline & 10 & $0.0151 *$ & $(0.0046,0.0257)$ \\
\hline & 20 & $0.0191 *$ & $(0.0086,0.0297)$ \\
\hline
\end{tabular}

* Denotes significance.

$\mathrm{H}_{2} \mathrm{O}=$ water, $\mathrm{ETOH}=70 \%$ isopropyl alcohol, $\mathrm{H}_{2} \mathrm{O}_{2}=3 \%$ hydrogen peroxide, $\mathrm{NaOCl}=5.25 \%$ sodium hypochlorite 


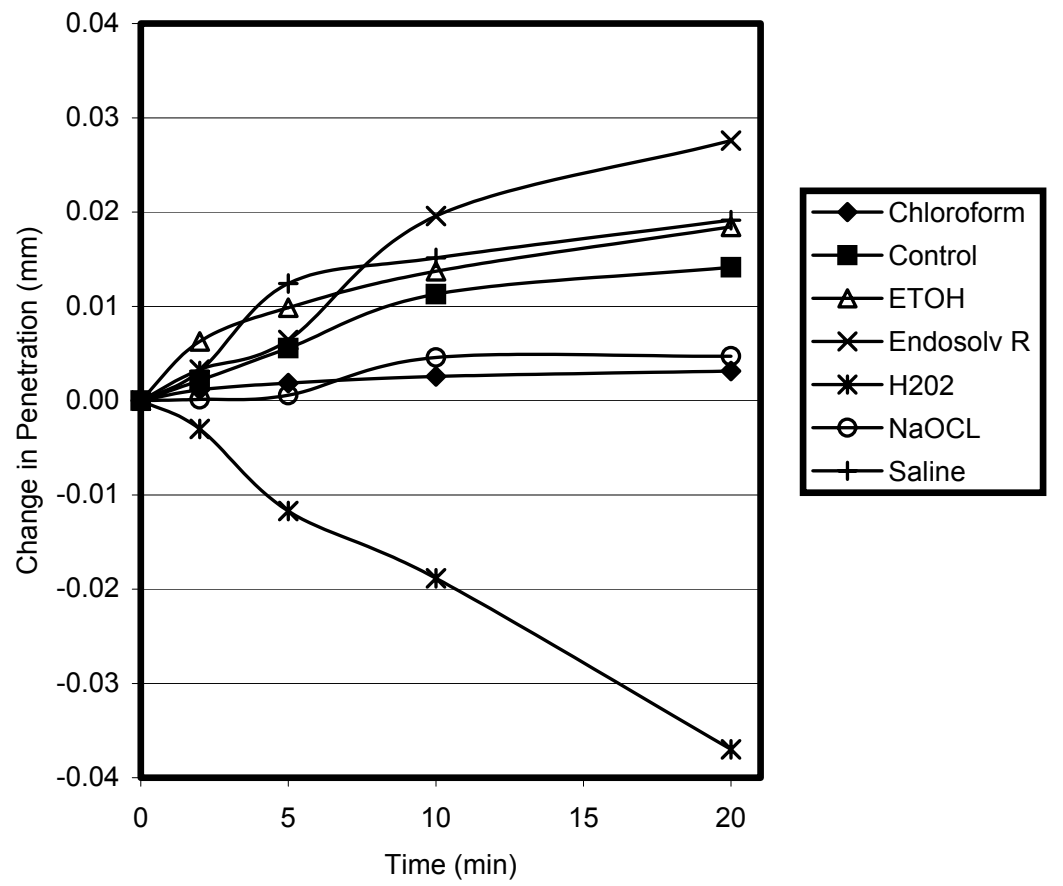

FIG 1. Penetration across time. 


\section{Discussion}

Resorcinol is a white, needle-like crystal chemical that has many industrial and medical uses. Resorcinol is also known by the following synonyms: Resorcin, 1-3 Dihydroxybenzene, m-Benezenediol, m-Hydroxyphenol, 3-Hydroxyphenol and 1,3Benezenediol. In 1957, resorcinol was introduced for use in endodontics in the form of "resinifying therapy" by Wang Man-en (9). Its use is contraindicated in deciduous teeth and immature permanent teeth in which the roots are not fully developed (10).

The clinical technique has been described by Wu and Wang (7). Briefly, the pulp chamber is unroofed and the pulp, if vital, is removed with a barbed broach. In fine canals in which a barbed broach cannot be inserted, the pulp tissues does not need to be removed; a fine reamer is used to form a passageway for the resorcinol material. The pulp residues are left in the apical part of the canal. If the pulp is necrotic, the canals are irrigated with $2 \%$ to $5 \%$ chloramine. The pulp cavity is dried with cotton pellets, and the resinifying agent is introduced with a fine reamer into the apical third of the canals. If vital pulp tissue remains apically, the agent is introduced more deeply to approach the apical foramen, and the excess is then absorbed with a small cotton roll. This procedure is repeated three or four times, and the final time the agent is left in the canals without being absorbed. Zinc oxide-eugenol paste is then pressed into the pulp chamber by means of a cotton pellet soaked with the resinifying agent. This is then covered with a layer of zinc phosphate cement and finally, the remaining cavity preparation is filled with amalgam. 
When compared to conventional root canal therapy, the following advantages of this technique have been cited (7): it is unnecessary to extirpate the pulp tissue entirely, to enlarge the canals, to use an additional antimicrobial agent for sterilizing the canals, to perform a bacteriologic examination of canals or to take radiographs to determine whether the canals are filled adequately. It has been concluded that this technique is quite simple, convenient, and can be used in the retreatment of cases that have failed because the root canals were very fine and/or curved, or in which broken instruments were present in the canals and could not by bypassed (7).

Using pastes as a sole root canal filling is generally not the treatment of choice. It has many disadvantages which include the lack of apical length control, inability to obtain a compact obturation, frequent presence of voids and possible severe toxicity if the paste material is extruded beyond the apical foramen (5). A specific disadvantage of resorcinol paste is the inability to retreat failed cases because of the hardness of the material once it has set. Resorcinol has been found to be able to infiltrate the dentinal tubules up to a depth of one-fourth to one-third the total length of the tubules (7). The infiltration ability of these paste materials combined with their hardness upon setting make it nearly impossible to remove the paste filling from canals. It would be beneficial if a solvent could be found that would soften the set resorcinol-formalin material in order to facilitate retreatment of these cases. A preliminary study by Vranas et al. (6) found that two solutions commonly used in endodontics, saline and sodium hypochlorite, had a softenening effect on resorcinol-formalin paste that had reached a hard set in a dappen dish model. However, due to the size of the dappen dish, a much larger surface area of the resorcinol-formalin 
paste was exposed to the air and to the solutions tested than would occur clinically within the confines of the root canal system. Therefore, in order to better simulate the clinical situation, the present study was designed to determine if similar results could be obtained using the root canals of extracted teeth as the model rather than dappen dishes (6).

In the present study the formulation of the resorcinol paste was that described by Wu and Wang (7) and differed somewhat from that used in the Vranas et al. (6) study. The main difference between the formulas was a difference in the amount of zinc oxide powder used. In the Wu and Wang study (7), a zinc oxide-eugenol paste is used in the chamber only, and zinc oxide powder is not mixed with the liquid that is placed in the root canals. They state that the resinifying agent is introduced into the apical third of the canals by insertion of a fine reamer; however, in their study on dog teeth, they state that the agent was "injected" into the canals. They do not state what they used to inject the agent into the teeth. In the present study, we found the solution was too fluid to allow placement into the canals with small files. In a pilot study it was found that the solution could best be delivered to the apical part of the canals by using a Monoject syringe with a 23 gauge needle. An exothermic reaction was noticed as the resorcinol-formalin combination was drawn up into the syringe. The solution began to bubble violently and the syringe felt warm to the touch. The mixture also set very rapidly ( $<5 \mathrm{~min})$. Only four or five tooth samples could be filled before the mixture began to set, and a new mixture had to be made.

Some observations in the present study were similar to those noted in previous studies $(5,7)$. In Cohen's (5) initial experiment, using $25 \mathrm{~mm}$ long capillary tubes with a $1.1 \mathrm{~mm}$ diameter, she observed shrinkage with all three formulations of the resorcinol- 
formalin pastes tested. She stated that the set mixture came out of the capillary tube in one piece. In the present study, a few of the specimens exhibited shrinkage, allowing the hard set paste to come out of the canal in one piece. These teeth did not exhibit any undercuts due to canal preparation using the \#7 Parapost drill. Wu and Wang (7) also noted that when exposed to air for several minutes, the resin in the canals began to shrink, and this gradually continued until only a thin layer of material adhered to the walls of the canal.

Chloroform was found to have no softening effect on the set resorcinol resin. This is similar to the results noted in two previous studies $(5,6)$. In the present study, Endosolv $\mathrm{R}^{\circledR}$ exhibited the greatest softening effect on the resin material at 10 and 20 minutes; however, this effect could not be detected clinically, and the paste was still visibly and tactilely hard. In other words, even though the dial gauge needle showed penetration with the Endosolv $\mathrm{R}^{\circledR}$, the amount of penetration was so small $(<0.03 \mathrm{~mm})$ that clinically this effect could not be detected with an endodontic explorer. This finding is similar to Cohen's (5) findings in her first experiment in which two of the resorcinol-formalin pastes, Traitement Spad ${ }^{\circledR}$ (Spad, France) and Resoplast ${ }^{\circledR}$ (Pierre Roland, France), lost less than 3\% of their original weight after contact with the solvents for one week, and a third resorcinol paste tested, Forfenan ${ }^{\circledR}$ (Septodont, France), lost less than $6 \%$ of its original weight. The pastes in her study were considered to be dissolved if there was a weight loss of more than $10 \%$. She also observed these three formaldehyde resin pastes to be porous. Since none of the solvents she tested exhibited an efficient dissolving effect on these pastes, a second experiment was performed, in which a cylinder of the set paste was immersed in the solvent for one hour or one week. Another solvent, dimethyl sulfoxide (DMSO) (Aldrich 
Chemical Company Inc., USA) was included for this second experiment since it is considered to be a universal solvent for organic substances. In the second experiment, Cohen (5) found the most efficient solvents for the resorcinol-formalin pastes to be Resosolv $^{\circledR}$ (Pierre Roland, France) and DMSO, and that DMSO completely dissolved Resoplast $^{\circledR}$. It appeared that increasing the contact surface area improved the ability of the solvent to dissolve the paste.

One interesting observation in the present study was the fact that hydrogen peroxide actually caused the needle of the dial gauge to move up instead of down. One explanation for this observation could be that the paste actually absorbed the $\mathrm{H}_{2} \mathrm{O}_{2}$, causing it to swell. Cohen (5) made this same observation with N2 paste and eugenol. Wu and Wang (7) also found that when a piece of resorcinol-formalin resin was immersed in water and soaked for 96 hours at body temperature, its volume became three times greater than before soaking, thus proving the expansion property of the resin.

Although none of the six common endodontic solutions tested in this study demonstrated a clinically detectable softening effect, the fact that Endosolv $\mathrm{R}^{\circledR}$ performed best warrants further investigation. Endosolv $\mathrm{R}^{\circledR}$ is formulated from formamide $(66.50 \mathrm{~g})$ and phenylethylic alcohol (33.50 g) and is recommended for softening of phenolic resin type fillings. Its composition is similar to Resosolv ${ }^{\circledR}$, which is made of dimethylformamide (98.60 g) and cinammon oil (100.00 g) (5). One technique for using Endosolv $\mathrm{R}^{\circledR}$ suggested by the manufacturer (10), is to utilize a two-visit treatment method. With this method, a small cotton pellet soaked in Endosolv $\mathrm{R}^{\circledR}$ is compressed into the chamber and, if possible, into the root canal orifice. The access is then sealed, and the 
tooth is re-opened several days later, at which time, hopefully, the hard paste will have softened, enabling its removal with files.

Further in vitro studies on resorcinol-formalin resin pastes are needed. The next step might be to compare, using extracted teeth as a model, the formulation of the paste tested in the present study with the three resorcinol-formalin pastes (Traitement Spad ${ }^{\circledR}$, Forfenan $^{\circledR}$, and Resoplast ${ }^{\circledR}$ ) tested in the Cohen (5) study. The three solvents (Endosolv $\mathrm{R}^{\circledR}$, Resosolv ${ }^{\circledR}$, and DMSO) that have been proven to be most efficient in the present study and in the Cohen (5) study could be tested by sealing them in contact with the paste for one to two weeks.

The present study ruled out several common endodontic solutions as possible solvents for resorcinol-formalin resin pastes. Until further in vitro and in vivo studies find an efficient solvent for these resin pastes, it is suggested that the paste in the coronal portion of the canal be removed by mechanical means (burs and ultrasonics) utilizing an operating microscope. Oftentimes, the paste may be removable because there are voids beneath the coronal portion of paste or the paste in the apical portion may not have polymerized completely (5). If the paste in the apical portion of the canal is hard, a cotton pellet soaked in Endosolv $\mathrm{R}^{\circledR}$ or Resosolv ${ }^{\circledR}$ could be sealed in the canal for one to two weeks, and then a second attempt made at removing the paste. An attempt should be made to remove these hard resin pastes and retreat the root canal system before condemning these teeth to extraction. 
Literature Cited 


\section{$\underline{\text { Literature Cited }}$}

1. Jeng HW, El Deeb ME. Removal of hard paste fillings from the root canal by ultrasonic instrumentation. J Endodon 1987;13:295-8.

2. Friedman S, Stabholz A, Tamse A. Endodontic retreatment-case selection and technique. Part 3. Retreatment techniques. J Endodon 1990; 16: 543-9.

3. Granin, AB. Personal correspondence translated from Russian. Date Unknown.

4. Sikri VK, Sikri P, Singh J, Manjri M, Khanna S. Resinifying therapy in endodontics. II-Histological and bacteriological evaluation. Indian J Dent Res 1996;7:51-3.

5. Cohen AG. The efficiency of different solvents used in the retreatment of paste-filled root canals [master's thesis]. Boston: Boston University, 1986: 1-100.

6. Vranas RN, Hartwell GR, Moon PC. The Effect of endodontic solutions on resorcinol-formalin paste. J Endodon 2003;29:69-72.

7. Wu M-K, Wang M-e. Clinical and experimental observations on resinifying therapy. Oral Surg Oral Med Oral Pathol 1986;62:441-8.

8. Wennberg A, Orstavik D. Evaluation of alternatives to chloroform in Endodontic practice. Endod Dent Traumatol 1989;5:234-7.

9. Sikri VK, Sikri P. Resinifying therapy in endodontics. A clinical and Radiological evaluation. Indian J Dent Res 1995;6:35-9.

10. Endosolv. Product for removing canal fillings. Manufacturer's insert. Septodont. Saint-Maur-des-Fosses Cedex, France. 09/2000. 


\section{$\underline{\text { VITA }}$}

Madelyn G. Gambrel was born on December 09, 1970 in Dallas, Texas. She graduated from Bonham High School, Bonham, Texas in 1989. She attended Baylor University in Waco, Texas where she received a Bachelor of Arts degree in Spanish in 1993. She then attended The University of Texas Health Science Center at San Antonio where she earned a Doctor of Dental Surgery degree in 1997. Subsequently, she was commissioned as an officer in the United States Navy. Upon graduation from dental school, she was stationed at the naval base in Rota, Spain for four years, where she served as a general dentist. She began specialty training in endodontics in July 2001 at Virginia Commonwealth University School of Dentistry in Richmond, Virginia, where she received a Certificate in Endodontics and a Master of Science degree in 2003. 